\title{
FASES DE LA INTERVENCIÓN SOCIAL CON INMIGRANTES
}

\author{
ANA M. ${ }^{a}$ ORTIZ DUQUE \\ Trabajadora Social
}

\section{INTRODUCCIÓN}

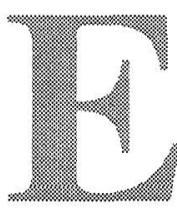

$\mathrm{n}$ todo proceso migratorio se dan unas etapas diferenciadas, tanto por el sentir del inmigrante y las expectativas que plantea, como por la relaciones que en ese momento tiene con la sociedad receptora, que han venido en llamarse generalmente «periodo de acogida» y «periodo de asentamiento», y que nosotros en el presente documento definimos para su mejor comprensión como:

1. Fase de Acogida. La llegada.

2. Fase Tutelada. La adaptación, el asentamiento.

3. Fase Autónoma. La inserción. Integración.

En cada una de ellas trataremos de analizar sus distintas connotaciones, que vienen dadas por las necesidades del inmigrante, las demandas que plantean y las respuestas que desde el Trabajo Social han de implementarse.

Hay que tener en cuenta que la duración de cada fase es distinta según el individuo, y que, en determinados casos, no se completa el proceso si el inmigrante decide retornar a su país.

También las funciones e intervenciones del trabajador social son variables según las fases, aunque existen unos principios básicos en cualquier intervención social con inmigrantes, que resumiríamos en:

- Respetar la diversidad cultural.

- Tener una actitud abierta, sin que en ello influya la situación legal de la persona en el país de acogida.

- Hacer posible que el inmigrante sea el actor de su propio cambio y desarrollo personal y social. Con ello se evitarán relaciones de proteccionismo y victimización.

- Tener una buena información sobre las leyes que regulan la estancia y residencia del inmigrante en el país.

- Primar la utilización de los recursos normalizados para toda la población, sobre aquellos específicos para el colectivo.

- Posibilitar la coordinación entre todas las entidades implicadas en el trabajo con inmigrantes (Administración, asociaciones, ONG's..).

- Favorecer el conocimiento de los beneficios que aportan los inmigrantes al país receptor: económicos, culturales..., y no sólo los problemas/necesidades o demandas que plantean. 
Antes de entrar en el análisis de las diferentes fases, sería conveniente valorar como rasgo común a todo inmigrante una voluntad tenaz de cambio, para lo cual están dispuestos a salir de su país, a afrontar los riesgos de un viaje, a conocer una nueva cultura, a aprender un idioma distinto, y a trabajar duramente en condiciones difíciles y precarias.

Para ello, y antes de empezar su proceso migratorio, van estableciendo una serie de contactos con la red de conocidos que ya se encuentran instalados en el país objeto de su iniciativa, los cuales les van orientando en los diferentes trámites legales que en éste deberán superar y las posibilidades de trabajo y vivienda que pueden encontrar, por otro lado procuran entablar los contactos necesarios para salvar las trabas burocráticas que les surgen en su país de origen.

En estos momentos se plantean la estancia fuera de su país de una forma temporal y como la solución a todos sus problemas, pues, piensan, influirá en la mejoría de su situación y la de su familia.

\section{FASE DE ACOGIDA}

En este primer momento el inmigrante puede sufrir un auténtico «shock» cuando llega al país receptor y se encuentra con una distinta cultura, costumbres, en algunos casos distinta lengua y religión e, incluso, una distinta concepción del tiempo y el espacio.

Otras características asociadas a esta fase son:

Se da con frecuencia un cambio en las expectativas de destino, debido a que no tienen previstas todas las variables que se van a encontrar, lo cual les hace desistir de llegar al sitio elegido quedándose muchos de ellos en lugares distintos al inicialmente escogido.

Optan por el máximo ahorro en la vivienda, y así ocupan edificaciones sin las mínimas condiciones de habitabilidad o bien viven en los pisos en una situación de hacinamiento; es una fase proclive a que se creen auténticos ghettos con los alojamientos. Por otra parte, el mundo urbano es algo desconocido para ellos, pues no traen este conocimiento de su país de origen al proceder mayoritariamente de áreas rurales.

En determinados colectivos se dan enormes dificultades idiomáticas, lo que conlleva una necesidad de aprendizaje de las mínimas bases para la comunicación.

En lo personal, en esta etapa nos encontramos con individuos solos, sin familias.

Aunque dispongan de permiso de trabajo, laboralmente se da una temporalidad y precarización del empleo y, además, la cualificación del trabajador es rebajada, si no obviada, a la hora de conseguir un 
puesto de trabajo; en el caso de las mujeres es incluso más patente que en el de los hombres.

En resumen, se ocupan en las actividades más marginales del mercado laboral, que son rechazadas por la población autóctona, por su precariedad, dureza, falta de remuneración y en actividades propias de la economía sumergida, esto último mucho más evidente en el inmigrante que no cuenta con el permiso de trabajo.

Atención también en esta fase a los problemas médico/sanitarios que se les plantean, dada la falta de cobertura adecuada que dé respuesta a dichos problemas.

\subsection{Funciones del Trabajador Social en la Fase de Acogida y Recursos}

La fase de Acogida es un momento clave en el proceso de intervención social que se lleva a cabo con el inmigrante. Las funciones del trabajador social vienen definidas ahora por la necesidad de cubrir las necesidades básicas de dichas personas, así como procurar orientarles en las gestiones que les permitan regular su residencia en el país receptor, dado que muchos llegan sin tener aún esta situación resuelta.

Para ello:

1) Contar con la suficiente preparación e información sobre el colectivo con el que se va a trabajar, con objeto de un mejor conocimiento de su realidad social.

2) Generar un clima de confianza en la primera entrevista.

3) Explicar la confidencialidad de todos los asuntos tratados.

4) Informar sobre derechos y recursos adecuados en su situación, que pueden ir desde prestaciones médicas, de vivienda, económicas, etc., evitando que se creen falsas esperanzas.

5) Asesorar en todos los trámites que les permitan obtener la residencia legal en el país.

\subsection{Recursos}

La situación del inmigrante recién llegado guarda diferencias con la del solicitante de asilo/refugio, ya que los primeros han tenido un tiempo para preparar su salida y entablar contactos con su red de conocidos en el país receptor, los cuales les informan de posibilidades de vivienda, trabajo..., trayendo estas contingencias más o menos cubiertas o previstas, no siendo el caso de los asilados/refugiados.

Sin embargo, es importante señalar que la situación de legalidad en el territorio nacional será lo que marque la posibilidad de acceso a los 
distintos recursos, como norma de funcionamiento de las distintas Administraciones, y en igualdad con los españoles.

En esta fase, tienen un papel primordial en la solución de conflictos, las ONGs y asociaciones de inmigrantes, dado que amplían su campo de actuación también a todas aquellas personas que aún no hayan obtenido la documentación acreditativa para permanecer en el país.

Dichas entidades reciben subvenciones para programas de acogida: tramitación de documentación, asistencia jurídica, clases de idioma ..., como para programas preventivos y asistenciales, tanto de carácter sanitario, de alojamiento, comedores, etc.

\section{FASE TUTELADA. EL ASENTAMIENTO. LA ADAPTACIÓN}

Esta etapa es quizás la más imprecisa de delimitar temporalmente, porque, mientras que la anterior se circunscribe a muy pocos meses, en esta fase de asentamiento el sujeto puede instalarse largo tiempo. Que no suceda esto depende de su capacidad para que «vivan desde muy pronto su adaptación como un trayecto lineal progresivo y relativamente largo (...) porque si espontáneamente concibe esa adaptación como cuestión de segmentos cortos de conducta -una adaptación aquí a las formas de trabajo y de allegar recursos para la supervivencia, alguna manera de acostumbrarse a las comidas que va a poder conseguir, a dificultosas condiciones de vivienda, etc.- no va a interesarse espontáneamente por otras cuestiones y va a instalarse en la repetición indefinida de unos ciclos diarios de vida que le encierran en lo más elemental y no le llevan a ninguna integración cultural superior»'.

En esta fase, se puede producir bien el fracaso completo del proceso migratorio, con el consiguiente regreso al país de origen después de una estancia totalmente negativa para sus expectativas, bien el estancamiento en una situación de conflictividad, dado que si en esta etapa la situación jurídica no entra en vías de solución, y con ello la posibilidad de su regularización laboral, se puede entrar en la realización de trabajos ilegales y de conductas delictivas, como es la prostitución en el caso de las mujeres, y la venta de drogas e incluso robos en los hombres.

Sin embargo, conforme se estabilizan en el mundo laboral y mejoran sus condiciones de trabajo se posibilita con ello:

Una mejora en la vivienda, aunque siguen habitando determinados barrios, dadas las dificultades para acceder al mercado de viviendas de alquiler: su elevado coste, las dificultades que plantea el autóctono

Tornos, Andrés: La familia, secreto de la integración. Comunicación presentada al Congreso, organizado por el Ayuntamiento de Madrid, con motivo del Año Internacional de la Familia. 
para alquilarles la vivienda, los problemas que ha suscitado la nueva Ley de Arrendamientos Urbanos -no olvidemos el plazo de hasta cinco años en el contrato, mientras que los permisos de residencia del inmigrante fluctúan, en las situaciones más corrientes, entre el año y los dos-.

Se asientan en las zonas más deterioradas de los centros urbanos, así como en determinados suburbios periféricos, rodeados de una población autóctona en gran medida desestructurada en lo personal y lo familiar y de conductas marginales, no comunes al inmigrante que allí habita.

En cualquier caso, se entiende que no tienen otra posibilidad de vivienda, dados los mínimos salarios que perciben y la necesidad de seguir mandando la mayor cantidad posible de dinero a su país.

En el plano laboral apreciamos que ya tienen asumido que lo importante es tener un empleo, aunque éste no responda a sus expectativas de cualificación laboral, y lo que se valora para llevarlo a cabo es el horario, los ingresos a percibir y las condiciones laborales que conlleva.

En lo personal, se empieza a perder la idea del retorno y se producen las primera reagrupaciones familiares. Ello afecta a la sociabilización del individuo, dado que hasta ese momento su comunicación ha sido básicamente con personas conocidas de la red social de su país de origen y siempre a niveles muy individuales.

La llegada de su esposa e hijos, sobre todo de estos últimos con las relaciones que establecen a través de la escuela, amigos y participando en actividades de tipo integrador, rompe la anterior tendencia.

El mayor conocimiento del idioma facilita, asimismo, esa sociabilización.

Sí que se aprecia que es la mujer, dentro del grupo familiar, quien más supedita su relación con el entorno a las necesidades familiares. Incluso por características culturales no quieren romper con ello. Además, su proceso migratorio -excepto en determinados colectivos: dominicanas, filipinas...- está excesivamente ligado al del marido, ya que su permiso de residencia a través de la reagrupación familiar no les posibilita trabajar, aunque con la aprobación del nuevo Reglamento que regula la Ley de Extranjería esto parece subsanarse.

\subsection{Funciones del Trabajador Social. Recursos.}

Al igual que en la fase de acogida eran las asociaciones y organizaciones no gubernamentales quienes tenían una acción fundamental, es ahora cuando el inmigrante se acerca en mayor medida a los Servicios 
Sociales, debiendo establecerse desde éstos intervenciones asistenciales, preventivas y promocionales.

Las principales demandas más usuales en esta etapa son:

- Información sobre prestaciones económicas a las que tienen derecho según la situación legal en que se encuentren.

- Empleo, ayuda en la consecución de un puesto de trabajo.

- Acceso a una vivienda.

- Reagrupación familiar: Información sobre como llevarla a cabo, y sobre cuales son las ayudas con que pueden contar al tener ya a su familia aquí.

- Prestaciones sanitarias, en aquellos casos que aún no tienen la cobertura de la Seguridad Social.

Las funciones que el trabajador social debe realizar en esta fase están ligadas a los objetivos de posibilitar la autonomía personal y/o social del inmigrante y el dominio de la vida cotidiana, así como prevenir las situaciones de crisis que les puedan sobrevenir por la pérdida de referencias culturales, sociales, lingüísticas y económicas.

Para ello, hay que establecer un contacto periódico a través de entrevistas, y plantear la intervención en base al proyecto personal de inmigrante. Este seguimiento posibilitará actuaciones como:

- Información sobre los temas relacionados con la vivienda y la búsqueda de alojamientos alternativos, etc.

La vivienda es uno de los recursos más normalizadores en la vida del inmigrante. Existen ayudas en el pago de fianzas y alquiler a través de los Servicios Sociales municipales y también a través del Proyecto de Provivienda de la Consejería de Sanidad y Servicios Sociales de la Comunidad de Madrid.

- Posibilitar su introducción en el mercado de trabajo, para ello utilizar las «Bolsas de Empleo», pudiendo llegar incluso a actuar como intermediarios entre empleados y empleadores. Es importante también favorecer su mejor capacitación laboral a través de cursos de formación.

- Procurarles medidas de apoyo en su núcleo familiar con especial atención a los menores, a través del seguimiento escolar, clases de apoyo, becas de comedores, etc.

- Facilitar el uso de las prestaciones sanitarias no sólo asistencialmente sino también de manera preventiva. Para ello, en el caso de aquellos que carezcan de Seguridad Social se pueden derivar a determinadas ONGs que tienen programas para este fin o a consultas sanitarias para inmigrantes irregulares, como las que ya están en funcionamiento en algún municipio del Área N.O de esta Comunidad.

- Se debe seguir trabajando la importancia del conocimiento del idioma, pues se conforman con tener unas nociones mínimas, desistiendo de asistir a clases en favor de otros cometidos, como buscar 
empleo, sin terminar de ver la importancia que tiene el conocimiento del idioma para lo anterior.

\section{FASE AUTÓNOMA. LA INTEGRACIÓN. LA INSERCIÓN}

Es en esta fase, que llamamos autónoma, donde el sujeto llega a la integración, lo cual significa que ha logrado la conjunción entre su adaptación al mundo que le rodea y la conservación de su propio yo. Esto no siempre lo consiguen. Por ello, toda intervención social con el colectivo ha de fundamentarse en la aplicación de medidas coherentes con ellos mismos y a la vez no discriminatorias.

A lo largo de estas etapas, que hemos venido describiendo, se ha dado lugar a una segunda y tercera generación de inmigrantes que han creado perspectivas, exigencias y problemas nuevos frente a los cuales la aceptación de la sociedad y la respuesta de las instituciones no siempre es rápida y adecuada.

Un paso adelante fundamental lo constituyó la reforma del artículo 2 de la Ley 11/1984, de 6 de junio de Servicios Sociales de la Comunidad de Madrid, con la que se consiguió extender los derechos que en ella se recogen a los extranjeros residentes en la Comunidad.

Por otro lado, no hay integración si el único que va experimentando un proceso de adaptación es el inmigrante. Ese mismo proceso de cambio y adecuación ha de irse dando en la sociedad receptora, para ello hay que conseguir una valoración positiva de la diversidad, lo que hará que se logren actitudes más tolerantes.

Durante esta fase, las intervenciones sociales resultan más esporádicas. El trabajo se centra, de manera más específica, en la llamada segunda generación, cuyo proceso de integración puede ser especialmente difícil al estar conviviendo en dos mundos: el de su familia, con todas las raíces socioculturales que implica, y en el mundo de la escuela, trabajo, etc... en resumen, de la sociedad que les rodea.

A modo de conclusiones, reflejar una serie de puntos que pensamos debe recoger todo plan o programa de intervención social con el colectivo de inmigrantes:

- Coordinación y apoyo entre las distintas administraciones: local, autonómica, y estatal.

- Es en el ámbito de las corporaciones locales, como administración pública más cerca al ciudadano, desde donde deben potenciarse las medidas más tangibles que promueven el logro de la Integración.

- Considerar que la colaboración con las ONGs, cuyo campo de actuación sea este colectivo, es fundamental.

- Potenciar el mayor número de medidas y actuaciones que fomenten 
la interculturalidad, marcando el respeto por las culturas distintas.

- Aplicar los recursos sociales como medio y no como fín, y siempre como factor de cambio dentro de una intervención social y global. 